\title{
1 Optimization of cellulose nanofibrils carbon aerogel fabrication using response surface methodology
}

\author{
Yujie Meng ${ }^{1,3}$, Xinzhou Wang ${ }^{1,2}$, Zhenggang $\mathrm{Wu}^{3}$, Siqun Wang ${ }^{1}$, Timothy M Young ${ }^{1 *}$ \\ ${ }^{1}$ Center for Renewable Carbon, Department of Forestry, Wildlife \& Fisheries, University of Tennessee \\ ${ }^{2}$ Department of Materials Science \& Engineering, Nanjing Forestry University \\ ${ }^{3}$ Oak Ridge National Laboratory, Oak Ridge, TN, USA
}

Abstract:

This research investigated the simultaneous effects of processing parameters in the making of carbon aerogel from cellulose nanofibrils (NFC). Variables such as peak temperature and heating rate at different levels were systematically investigated with the goal of parameter optimization using response surface methodology (RSM). A facecentered central composite design (CCF) was used to evaluate the feasible range of process conditions where the levels of peak temperature and heating rate were varied at levels ranging from $230{ }^{\circ} \mathrm{C}$ to $320{ }^{\circ} \mathrm{C}$. Results indicated that the quadratic model developed for the response surface was adequate for the prediction of optimal parameters.

23 Response surface predictions were developed to explore the integrated and feasible 24 operating space. Optimum conditions were: $300{ }^{\circ} \mathrm{C}$ peak temperature and a heating rate of $8.00{ }^{\circ} \mathrm{C} / \mathrm{min}$. The carbon aerogel achieved approximately $90.10 \mathrm{~g} / \mathrm{g}$ of the normalized oil absorption capacity despite a weight reduction percentage of $82 \%$.

28 Keywords: Carbon aerogel, cellulose nanofibrils, oil absorption, optimization, response

29 surface methodology (RSM) 


\section{Introduction:}

32 Oil recovery from oil spills using absorbent materials has recently attracted extensive

33 scientific and practical interest. Among numerous materials, absorbents from natural

34 precursors are of the most interest. Despite the fact that conventional nature absorbent

35 materials are widely used for large-scale oil spill cleanup, the hydrophilic nature of these

36 materials drastically hampers the oil absorption efficiency. As a result, new absorption

37 materials with hydrophobic properties are of great interest. Examples include carbon

38 foams, graphene aerogel, carbon nanotube aerogel, carbon fiber aerogel, and carbon

39 microbelts aerogel [1-7].

40 Nanocellulose is a promising new material not only because it is a bio-based, 41 sustainable, nontoxic, abundant, and renewable resource; but it also has unique intrinsic

42 properties [8-11]. In particular, cellulose nanofibrils (NFC) consists of long, flexible

43 fibers cleaved from the hierarchy of plant or wood cellulose by mechanical processes

44 [12-14]. Among these superior properties, thermal stability is of great interest [15]. Since

45 the development of the carbon structures from this potential green alternative, numerous

46 promising applications are in development, ranging from electrochemical energy storage,

47 hydrogen storage, to super capacitors etc. [16-18]. The mechanism and the structure-

48 properties relationships of carbonaceous material have been studied [19-21]. For

49 cellulose material, the carbonization is mainly dominated by two reactions including

50 degradation and depolymerization [22]. In addition, heating temperature, and heating rate

51 during carbonation have been demonstrated as key factors that influence the mechanical

52 properties [23]. However, the effect of these two parameters on the porous and adsorption

53 properties is limited. Our previous study successfully developed a super-light,

54 hydrophobic carbon aerogel with highly oil absorption properties using microfibril

55 cellulose as the raw material [24]. We demonstrated a green synthesis approach involves

56 freeze-drying and carbonization process to achieve 3D porous network structure and

57 hydrophobic properties. In addition, in order to achieve maximum oil absorption capacity

58 and increase the final carbon yield, research attention is focused on two factors: 'peak

59 temperature' and 'heating rate' during carbonization.

60 There are some disadvantages of studying the influence of the factor on the response

61 one-factor at a time, e.g., it is time consuming involving many experiments and does not 
62 allow for the examination of interaction effects. Design of experiments (DOE) is a tool

63 that allows for parameter optimization, especially in cases where many factors are

64 involved and varied simultaneously. Among the different methods of experimental

65 design, Response Surface Methodology (RSM) is an effective statistical modeling tool. It

66 can be used in studies including biochemical systems, biotechnology, nanotechnology,

67 etc. [25]. RSM allows for: expanded inference; the study of interactions; and parameter

68 optimization. RSM is considered a formal experimental design technique that maximizes

69 inference while minimizing the number of experimental runs.

70 The research focus of this study was to estimate the effect of key factors on the 71 response of oil absorption and weight reduction, and to determine the optimal values for 72 processing carbon aerogel. This approach quantified the relationship between NFC 73 aerogel carbonization processing conditions and carbon aerogel's physical properties.

74 The RSM used two variables, 'peak temperature' and 'heating rate' on the oil absorption 75 capacity and final weight reduction of carbon aerogel. In addition, physical properties, 76 internal morphology, and thermal properties of carbon aerogel were investigated.

\section{Material and methods:}

\section{Material:}

79 Cellulose nanofibrils with a solid content of 5\% were obtained from commercial 80 sources (University of Maine, USA). Cross-linker KymeneTM resin was commercially 81 available (Ashland Hercules Inc., USA).

\section{Preparation of NFC aerogel and carbon aerogel:}

83 NFC suspension with concentration of $1.5 \mathrm{wt} \%$ and cross linker resin (5 wt $\%$ of dry 84 NFC) was mixed and poured into open-ended copper pipes (1.50 inch in length and 0.81 85 inch in diameter) and sealed with aluminum foil. The samples were then placed into 86 liquid nitrogen for one minute for rapidly freezing, following which the aluminum foil 87 was removed and the samples were freeze-dried in a vacuum lyophilizer (Labconco, Inc., 88 Kansas City, MO) at $-51{ }^{\circ} \mathrm{C}$ for three days. Ultralight sponge-like aerogel was obtained. 89 Samples were oven-heated at $120^{\circ} \mathrm{C}$ for 3 hours to promote cross-linking in order to 90 form a three-dimensional network. Carbonized on NFC aerogel was carried out under 91 flowing nitrogen $(20 \mathrm{ml} / \mathrm{min})$ using a tube furnace (Thermo Scientific) by heating the 
92 sample from room temperature to $180{ }^{\circ} \mathrm{C}$ with a heating rate of $10{ }^{\circ} \mathrm{C} / \mathrm{min}$, followed by

93 increasing the temperature from 180 to $230{ }^{\circ} \mathrm{C}$ at a rate of $5{ }^{\circ} \mathrm{C} / \mathrm{min}$, and increasing the

94 temperature from 230 to $320^{\circ} \mathrm{C}$ at different heating rates ranging from 0.20 to $5{ }^{\circ} \mathrm{C} / \mathrm{min}$.

95 Finally, samples were further heat treated by increasing the temperature from $320^{\circ} \mathrm{C}$ to

96 peak temperatures of $400{ }^{\circ} \mathrm{C}, 700{ }^{\circ} \mathrm{C}$ and $1000{ }^{\circ} \mathrm{C}$ respectively at a rate of $5{ }^{\circ} \mathrm{C} / \mathrm{min}$ in

97 nitrogen and holding for $15 \mathrm{~min}$. Samples were then cooled to room temperature.

\section{Oil sorption experiments}

99 Oil absorption experiments were carried out using paraffin oil (BP PLC gas station).

100 Carbon aerogel sponges were weighed first and immersed into oil. After the immersion,

101 the sponge was taken out, drained for 30 seconds to wipe away the excess oil, and

102 immediately transferred to a tarred pan. Sample was measured by weight and this process

103 was repeated until carbon aerogels reached sorption saturation. The oil absorption

104 capacity could be defined as the ratio between the weight of absorbed carbon aerogel and

105 the weight of dried carbon aerogel.

\section{Structure characterization of NFC aerogel and carbon aerogel}

107 The inner structures of NFC aerogel and carbon aerogel were imaged using scanning 108 electron microscopy (SEM, Zeiss Auriga SEM/FIB crossbeam workstation). NFC aerogel

109 was coated with a thin layer of gold to provide conductivity and to protect the sample

110 from electron beam damage. The ultrastructure of the carbon aerogel was characterized

111 by transmission electron microscopy (TEM, Zeiss Libra 200 MC). Carbonized aerogel

112 was ground into powder and dispersed into distilled water. TEM samples were prepared

113 by depositing suspension drops $(0.001 \% \mathrm{w} / \mathrm{v}$ in water) on amorphous lacey carbon-coated

114 electron microscope grids and were then allowed to dry. The TEM was operated at a 200

$115 \mathrm{kV}$ accelerating voltage. Thermal stability and carbonization yield were determined using

116 thermogravimetric analyzers (TGA; Perkin-Elmer 7 series; Perkin-Elmer Cetus

117 Instruments, Norwalk, CT). The heating program was set up exactly the same to mimic

118 the carbonization process.

119 


\section{Experimental design:}

121 A face-centered central composite design (CCF), where the red stars are at the center 122 of each face of the factorial space, was employed for the designed experiment of this 123 research. Fig. 1 illustrates the diagram of CCF designs for two factors. The CCF provides 124 predictions over the entire design space. Effects of two factors, namely 'peak 125 temperature' and 'heating rate' on two responses of oil absorption and weight reduction 126 respectively were evaluated. There were three levels for each factor as shown in Table 1. 127 The levels were determined based on previous knowledge and screening experiments.

128 The number of experiments required for the $2^{2}$ full factorial CCF experiments were 129 calculated according to the equation $\left(\mathrm{N}=2^{k}+2 k+n c\right)$, where $k$ represents the number of 130 factors, $2^{\mathrm{k}}$ is the number of factorial points, $2 k$ stands for the axial points (star points) on 131 the face, while $n c$ means the number of replicates at the center point, in this case $n=2$. 132 The design had a total of 20 runs including 8 factorial points, 8 axial points (star points) 133 and 4 replicates at the center points.

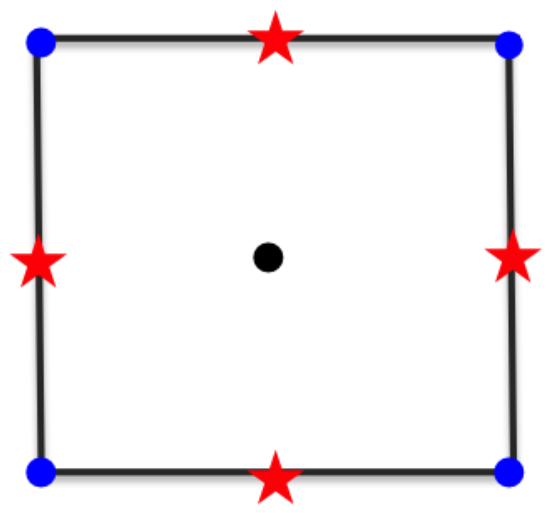


Table 1 Independent variables and their values for oil absorption capacity

\begin{tabular}{cccc}
\hline \multirow{2}{*}{ Factor } & \multicolumn{3}{c}{ Level } \\
\cline { 2 - 4 } & Low & Center & High \\
\hline Peak temperature $\left({ }^{\circ} \mathrm{C}\right)$ & 400 & 700 & 1000 \\
Heating rate $\left({ }^{\circ} \mathrm{C} / \mathrm{min}\right)$ & 0.20 & 2 & 10 \\
\hline
\end{tabular}

\section{Statistical analysis}

142 The relationship between the variables and each response Y could be described as a 143 second-degree polynomial quadratic equation:

$$
Y=b_{0}+\sum_{i=1}^{k} b_{i} x_{i}+\sum_{i=1}^{k} b_{i i} x_{i}^{2}+\sum_{i=1, j=i+1}^{k} b_{i j} x_{i} x_{j}+\varepsilon
$$

where $b_{0}$ is the constant value, $b_{i}$ is the regression coefficients of the individual linear effect, $b_{i i}$ is the quadratic effect and $b_{i j}$ is the interaction between the variables; $k$ is the number of factors studied ( $\mathrm{k}=2$ in this case).

151 response surface and contour plots were developed in JMP software (version10, SAS

152 Institute; Cary, NC, USA). The coefficients with small $p$-value less than 0.05 were

153 considered to be statistically significant effect.

\section{Results and discussion:}

\section{Observation of structure and physical properties}

156 The inner structure of both NFC aerogel and carbon aerogel heat-treated at $1000{ }^{\circ} \mathrm{C}$ 157 was imaged using scanning electron microscopy (SEM), and the ultrastructure of carbon 158 aerogel was investigated using TEM (Fig. 2). Both aerogel and carbon aerogel are 159 composed of a three-dimensional network structure with interconnected microfibrils. It is 160 the 3D porous network structure that makes the derived carbon aerogel possessing an 161 ultralow density. Effects of heating temperature and heating rate on physical properties of 162 NFC aerogel and carbon aerogel were evaluated and compared. From the bright-filed 163 TEM image in Fig. 2 (c) and line profile (d), it is clearly and easily observed that carbon 164 aerogel heat-treated at $1000^{\circ} \mathrm{C}$ is mainly composited of stacks of ribbon-like graphitic 165 layers with a calculated spacing of $0.37 \mathrm{~nm}$. The graphite ribbons orientated randomly 166 and tangled in a complicated manner. In the contrast, graphite structure was barely 
167 observed in carbon aerogel heat-treated at $700{ }^{\circ} \mathrm{C}$ and $400{ }^{\circ} \mathrm{C}$, respectively. Results also 168 provided information that the bulk density of NFC aerogel was $0.02 \mathrm{~g} / \mathrm{cm}^{3}$ and it 169 decreased to $0.01 \mathrm{~g} / \mathrm{cm}^{3}$ after carbonization at various temperatures. Fig. 2 (e) presents an 170 image of NFC aerogel sitting on the flower, visually indicates the ultralight properties. 171 Fig. 2 (f) shows the photograph of water droplet supported on the carbon aerogel, 172 indicating its hydrophobicity. It is believed that hydrophilic functional groups such as $173 \mathrm{C}=\mathrm{O}, \mathrm{C}-\mathrm{O},-\mathrm{OH}$ and $\mathrm{C}-\mathrm{O}-\mathrm{C}$ existed in NFC aerogel could be largely removed during 174 carbonization, leading to the reverse of wetting properties[24].

175 

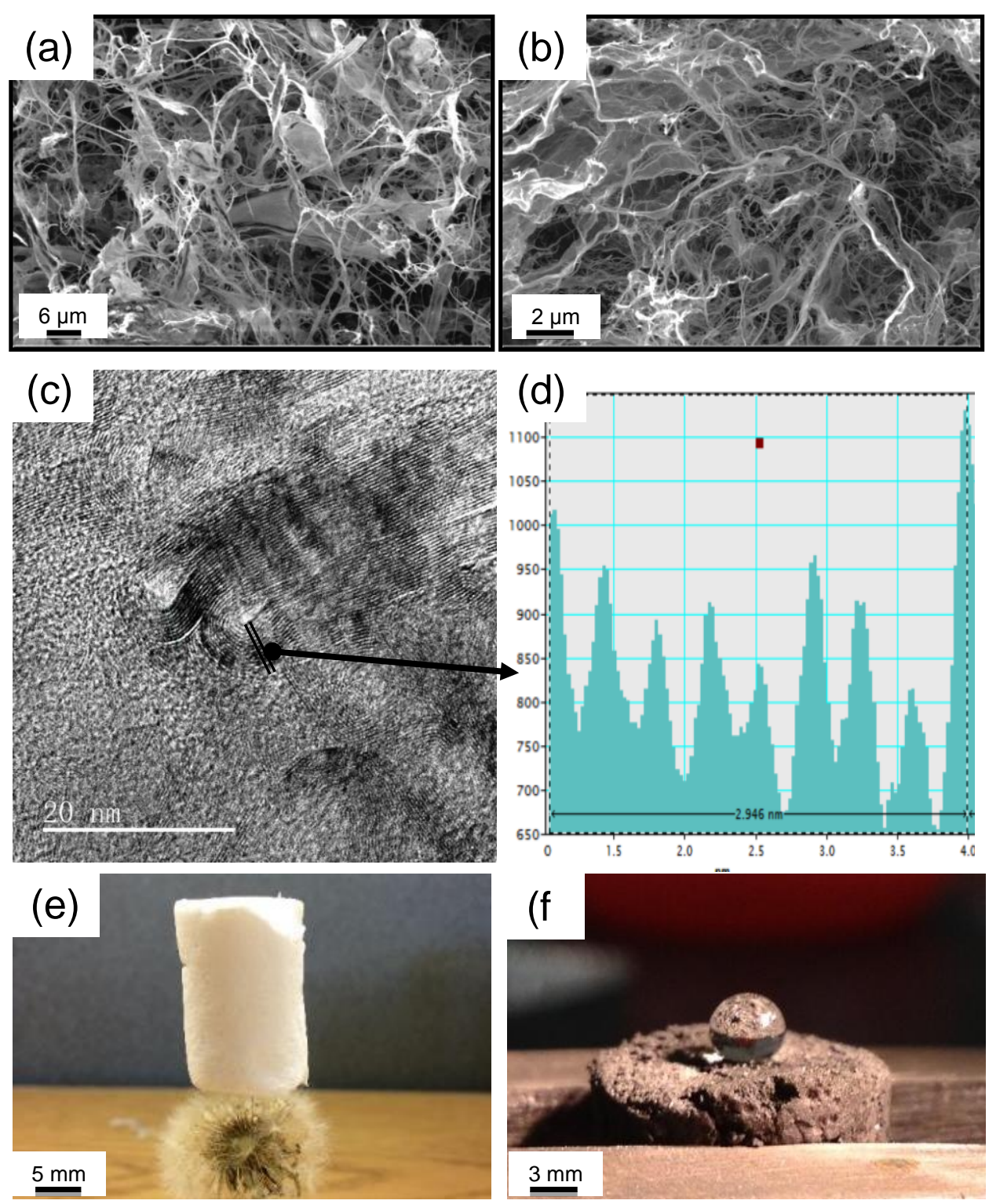

Fig. 2 SEM images of (a) NFC aerogel, (b) carbon aerogel heat treated at $1000{ }^{\circ} \mathrm{C}$, (c) TEM images of graphite domain in the structure of carbon aerogel heat treated at $1000^{\circ} \mathrm{C}$, (d) line profile of graphite domain from the same sample, (e) NFC aerogel sitting on the flower and (f)

\section{Factor optimization by response surface methodology}

184 The central composite design and the observed dependent variables data are 185 summarized in Table 2. The variable coded as '-' and '+' represent the 'low' and 'high'

186 levels of the studied variables, ' 0 ' represents the center point of the design, letters ' $a$ ' and

187 ' $\mathrm{A}$ ' represent the axial points of the design. The oil absorption capacity ranged from

18871.94 to $94.18 \mathrm{~g} / \mathrm{g}$ at design point of "11" and "2", respectively. The weight reduction 
ranged from 66.12 to $87.89 \%$, at design points of " 2 " and " 17 ", respectively. Generally,

190 cellulose carbonization is a complex process that usually involves dehydration and

191 depolymerization [22]. Ideally, the carbon yield of NFC is $44.40 \%$ according to the

192 molecular stoichiometry $\left(\mathrm{C}_{6} \mathrm{H}_{10} \mathrm{O}_{5}\right)_{n}$. However, the depolymerization of the

193 macromolecular chains during carbonization usually happens with the formation of

194 carbon monoxide, and carbon dioxide, aldehydes, organic acid, and tars, which takes

195 away more carbons, leading to a low carbon yield. It has been shown that heating rate

196 plays an important role on the char yield during carbonization [26]. A fast heating rate

197 can create small volatile fragments in cellulose structure, leading to a major mass loss

198 when increasing the temperature. Usually, a slow heating rate of a few ${ }^{\circ} \mathrm{C} / \mathrm{min}$ is

199 suggested in order to increase carbon yield. The cellulose structure will experience a

200 series of changes when heating temperature is increased. The structure of the carbon

201 residual has a tendency to become well-ordered during the heat treatment when

202 temperatures range from $400{ }^{\circ} \mathrm{C}$ to $900{ }^{\circ} \mathrm{C}$. Graphitization usually starts when the heat

203 treatment exceeds $900{ }^{\circ} \mathrm{C}$. Based on previous studies on cellulose carbonization, the

204 heating temperature is believed to be an important factor that affects carbon yield and

205 may also has influence on the oil absorption capacity [22]. 
Table 2 Second-order central composite on face design, experimental data for three-level-two factors response surface analysis

\begin{tabular}{cccccc}
\hline \multirow{2}{*}{$\begin{array}{c}\text { Serial } \\
\text { number }\end{array}$} & Pattern & $\begin{array}{c}\text { Independent variable } \\
\text { Temprature } \\
\left({ }^{\circ} \mathbf{C}\right)\end{array}$ & $\begin{array}{c}\text { Heating rate } \\
\left({ }^{\circ} \mathbf{C} / \mathbf{m i n}\right)\end{array}$ & $\begin{array}{c}\text { Oil absorption } \\
\text { capacity } \mathbf{Q}_{\mathbf{s}} \\
(\mathbf{g} / \mathbf{g})\end{array}$ & $\begin{array}{c}\text { Weight } \\
\text { reduction } \\
(\mathbf{\%})\end{array}$ \\
\hline 1 & -- & 400 & 0.2 & 90.69 & 73.58 \\
2 & -- & 400 & 0.2 & 94.18 & 66.12 \\
3 & $\mathrm{a} 0$ & 400 & 2 & 89.18 & 84.87 \\
4 & $\mathrm{a} 0$ & 400 & 2 & 83.61 & 82.41 \\
5 & -+ & 400 & 10 & 82.49 & 84.29 \\
6 & -+ & 400 & 10 & 87.95 & 80.62 \\
7 & $0 \mathrm{a}$ & 700 & 0.2 & 78.65 & 87.05 \\
8 & $0 \mathrm{a}$ & 700 & 0.2 & 74.53 & 85.29 \\
9 & 00 & 700 & 2 & 76.93 & 85.72 \\
10 & 00 & 700 & 2 & 77.52 & 87.53 \\
11 & 00 & 700 & 2 & 71.94 & 83.38 \\
12 & 00 & 700 & 2 & 74.1 & 80.91 \\
13 & $0 \mathrm{~A}$ & 700 & 10 & 72.8 & 87.60 \\
14 & $0 \mathrm{~A}$ & 700 & 10 & 70.44 & 84.52 \\
15 & +- & 1000 & 0.2 & 74.11 & 73.43 \\
16 & +- & 1000 & 0.2 & 74.97 & 73.93 \\
17 & A0 & 1000 & 2 & 68.23 & 87.89 \\
18 & A0 & 1000 & 2 & 76.13 & 84.45 \\
19 & ++ & 1000 & 10 & 73.31 & 85.47 \\
20 & ++ & 1000 & 10 & 74.86 & 87.13 \\
\hline
\end{tabular}

The statistical analysis results of the optimization experimentation for two variables

210 The goodness of fit analysis was employed to estimate how well the statistical models

211 describe the experimental data. The coefficient of determination R-squared closes to 1

212 indicates a good goodness of fit. The actual by predicted plot is shown in Fig 3, where

213 there was a strong correlation between predicted and actual oil absorption capacities $\left(\mathrm{R}^{2}=\right.$

214 0.88). Relatively low $\mathrm{R}^{2}=0.60$ was observed for response of carbon aerogel weight

215 reduction. The observed results demonstrate that both responses of oil absorption

216 capacity and weight reduction are affected by experiment factors.

217 The response model for oil absorption capacity is:

$219 Y=71.38-0.023(A-700)-0.43(B-5.1)+10^{-3}(A-700)(B-5.1)+$

$22010^{-4}(A-700)^{2}+0.15(B-5.1)^{2}$

221 where $Y$ is the response variable of normalized oil absorption capacity, $A$ and $B$ are the

222 'peak temperature' and 'heating rate,' respectively.

223 The response model for weight reduction is: 
226 where $W$ is the response variable of carbon aerogel weight reduction, $A$ and $B$ are the 227 'peak temperature' and 'heating rate', respectively.

(a)

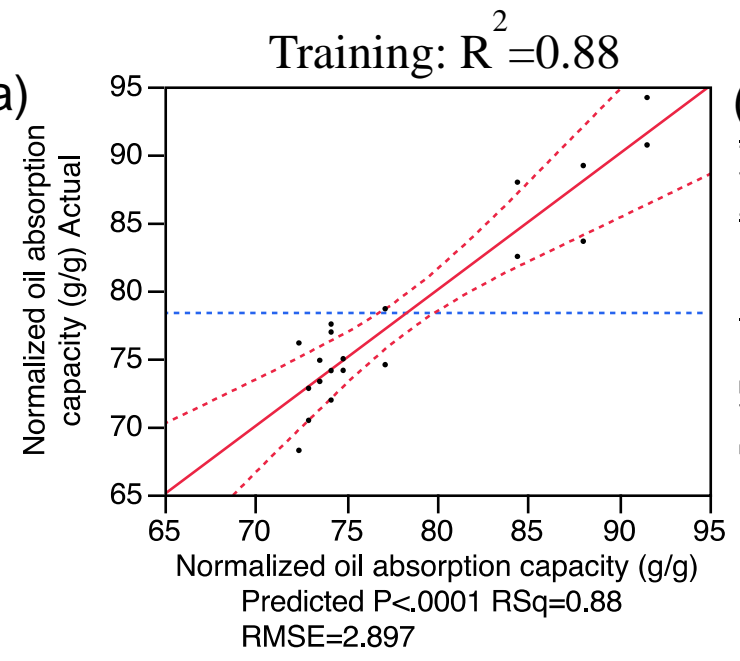

Predicted $\mathrm{P}<.0001 \mathrm{RSq}=0.88$

Training: $\mathrm{R}^{2}=0.60$

(b)

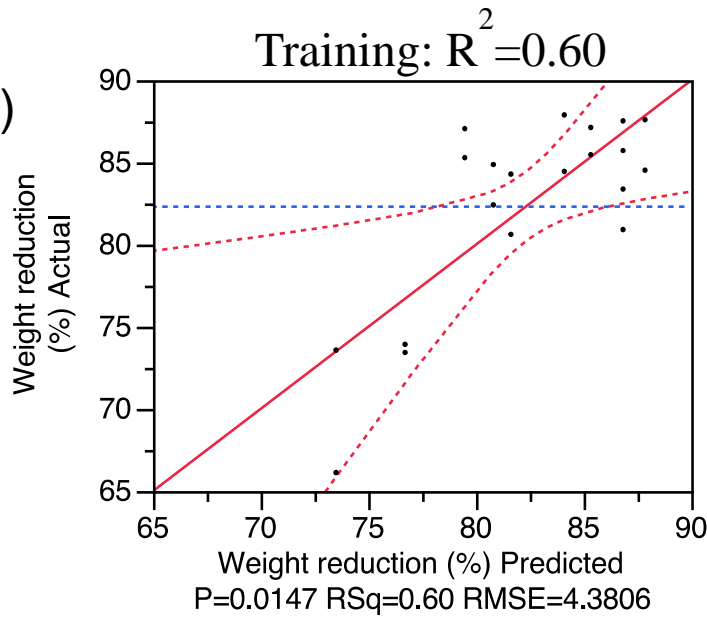

(c)
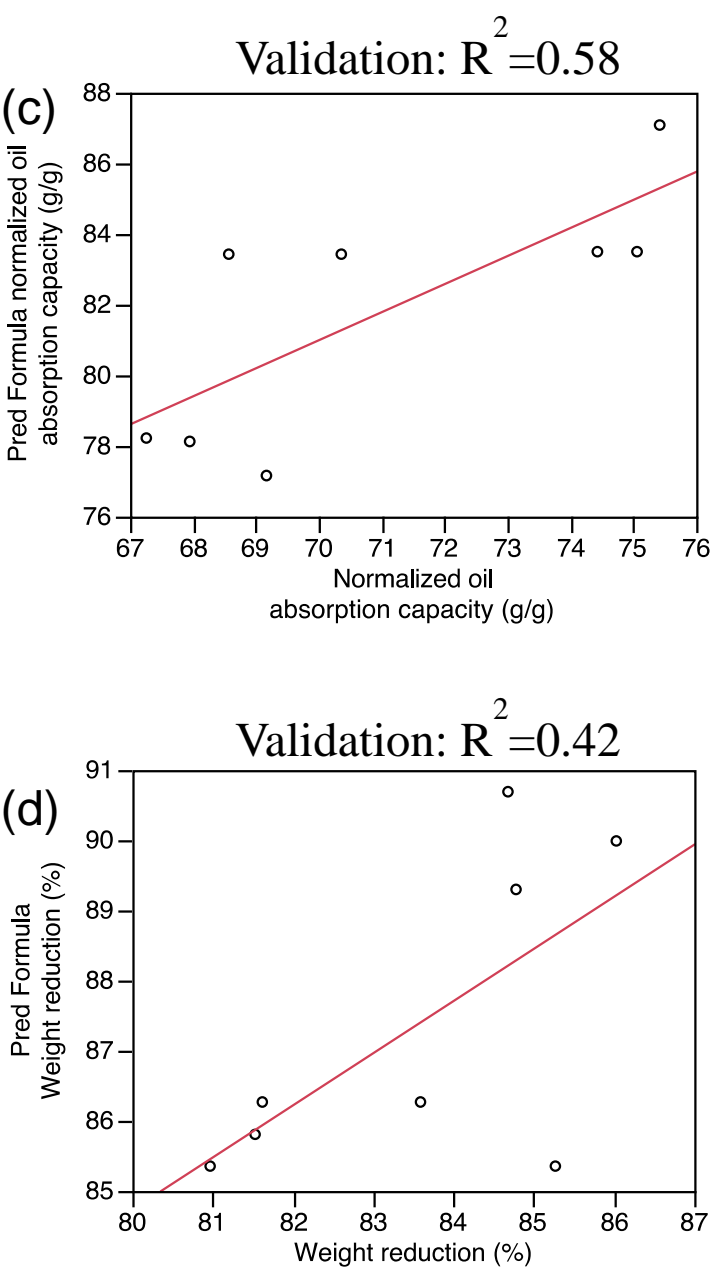

228

Fig. 3 Goodness-of fit of training data set (a) between predicted values obtained via partial least squares fitting and experimentally measured oil absorption capacity values, (b) between predicted values obtained and experimentally measured weight reduction; validation data set (c) between predicted values obtained via partial least squares fitting and experimentally measured oil absorption capacity values and (d) between predicted values obtained and experimentally measured weight reduction

The analysis of variance for the second-order regression equation is summarized in 
238 Table 3 . The $\mathrm{F}$ value ${ }^{1}$ for model of normalized oil absorption capacity (21.06) was 10 239 times greater than the critical $\mathrm{F}$ value (2.96), suggesting a statistical significance.

240 However, the $\mathrm{F}$ value for model of weight reduction (4.23) was greater than critical $\mathrm{F}$ 241 value but less than 3-5 times greater, indicating a fairly low significance of model [27]. 242 The significance of each coefficient is evaluated by individual $p$ value. The lower the $p$ 243 value, more significant of the variable. In the model for normalized oil absorption 244 capacity, regression analysis revealed that the liner model terms, which are peak 245 temperature, heating rate, and the quadratic model terms peak tem ${ }^{2}$ made important 246 contribution to the whole model with $p$ values smaller than 0.05 . The order of the terms 247 regarding to the significant are: peak temperature $(\mathrm{p}<0.0001)$, peak tem ${ }^{2}(\mathrm{p}=0.0005)$ and 248 heating rate $(\mathrm{p}=0.0245)$. Carbon aerogel's volume was associated with oil absorption 249 capacity. The volume was estimated to be $3.7 \mathrm{~mm}^{3}, 2.16 \mathrm{~mm}^{3}$ and $2.51 \mathrm{~mm}^{3}$ 250 corresponding to carbon aerogel heat-treated at $400{ }^{\circ} \mathrm{C}, 700{ }^{\circ} \mathrm{C}$ and $1000{ }^{\circ} \mathrm{C}$, 251 respectively. It seems volume shrinkage is small at low heating temperature while large 252 at high temperature. Similar result was also reported by Tang et al, that a plot was drawn 253 describing the shrinkage percentage as a function of heating temperature [19].

254 Similarly, in the model for weight reduction, regression analysis revealed that the 255 liner model term, heating rate and the quadratic model terms, peak tem ${ }^{2}$ and heating rate ${ }^{2}$ 256 were significant with $\mathrm{p}$ values smaller than 0.05 . The order of the terms regarding to the 257 significant is: heating rate $(\mathrm{p}=0.0052)$, heating rate $^{2}(\mathrm{p}=0.0184)$ and peak tem ${ }^{2}$ 258 ( $\mathrm{p}=0.0489)$. There was no significant interaction parameter contribute to the model given 259 high $\mathrm{p}$ values shown in Table 3. Carbonization temperature exhibited a negative effect on 260 the char yield, consistent with the tendency found by previous studies available in the 261 literature [20]. The carbon yield is apparently sensitive to the heating rate, provided by 262 the fact that slowing heating rate dramatically increase the carbon yield in early research 263 [28].

\footnotetext{
${ }^{1}$ Fischer variance values (F value), denoted as the model mean square divided by the error mean square, were 21.06 and 4.23 for two models respectively. F values calculated from ANOVA regression were compared with critical $\mathrm{F}$ value, which is $\mathrm{F}_{0.05,5,14}=2.96$ for both models, where 0.05 is the false-rejection probability, 5 is the degree of freedom of regression and 14 is the degree of freedom of residual error.
} 
Table 3 Analysis of Variance (ANOVA) for response surface quadratic model

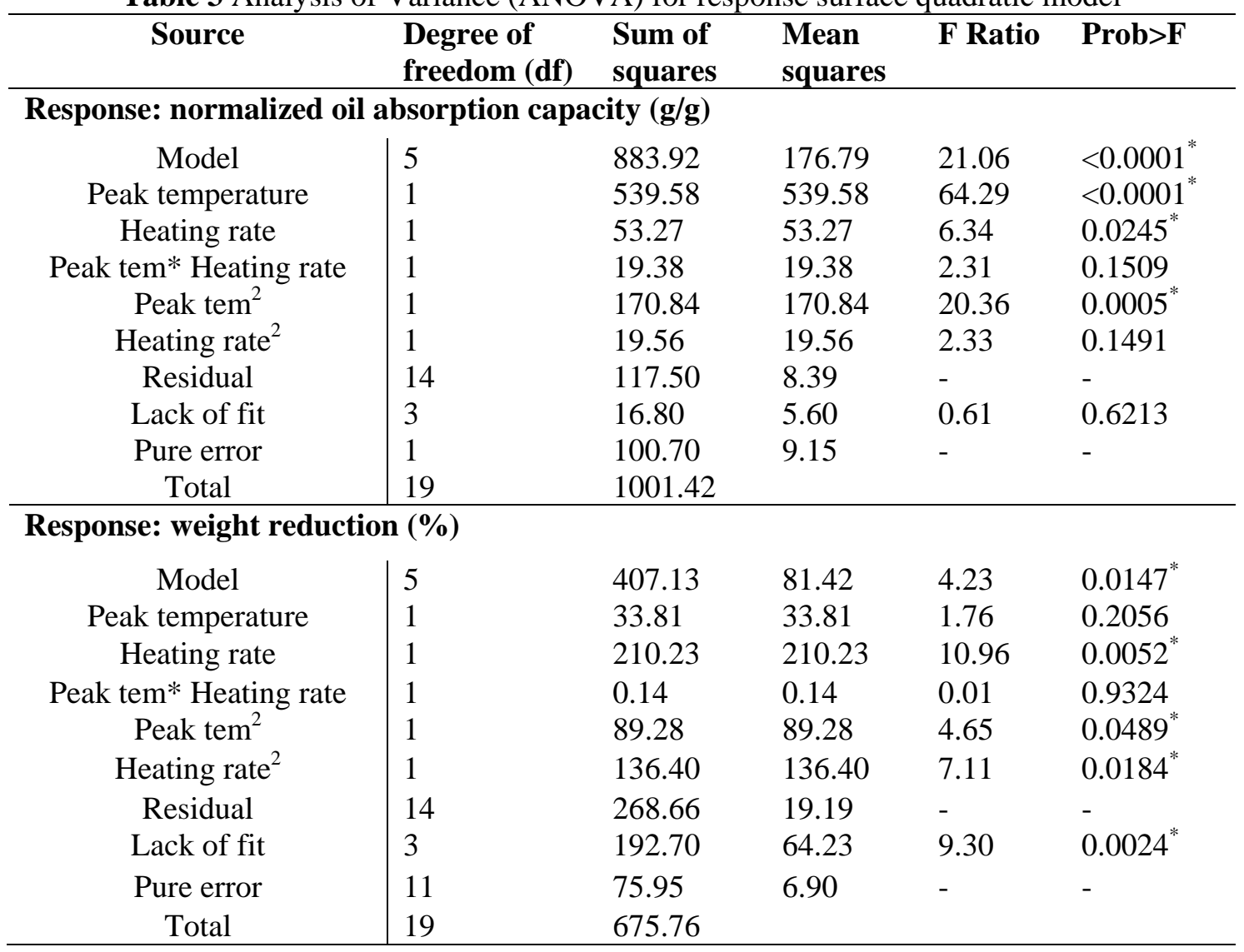


Table 4 Estimated regression coefficients for normalized oil absorption capacity and weight

\begin{tabular}{|c|c|c|c|c|c|c|}
\hline Term & Estimate & Std Error & t Ratio & $\operatorname{Prob}>|t|$ & $\begin{array}{l}\text { Lower } \\
95 \%\end{array}$ & $\begin{array}{l}\text { Upper } \\
95 \%\end{array}$ \\
\hline \multicolumn{7}{|c|}{ Normalized oil absorption (g/g) } \\
\hline Intercept & 71.37 & 2.06 & 34.51 & $<0.0001$ & 66.94 & 75.81 \\
\hline Peak tem & -6.90 & 0.86 & -0.80 & $<0.0001$ & -8.75 & -5.05 \\
\hline Peak tem ${ }^{2}$ & 6.05 & 1.34 & 4.51 & 0.0005 & 3.17 & 8.93 \\
\hline Heating rate & -2.10 & 0.84 & -2.52 & 0.0245 & -3.90 & -0.31 \\
\hline \multicolumn{7}{|c|}{ Weight reduction (\%) } \\
\hline Intercept & 93.36 & 3.13 & 29.85 & $<0.0001$ & & \\
\hline Heating rate & 4.19 & 1.26 & 3.31 & 0.0052 & 1.47 & 6.90 \\
\hline Heating rate ${ }^{2}$ & -9.69 & 3.63 & -2.67 & 0.0184 & -17.49 & -1.89 \\
\hline Peak tem ${ }^{2}$ & -4.37 & 2.02 & -2.16 & 0.0489 & -8.72 & -0.02 \\
\hline
\end{tabular}

270

\section{Optimization of normalized oil absorption capacity / weight reduction of carbon}

\section{2 aerogel and model validation}

273 The response surfaces of the interaction effects by the combination of two test

274 variables are plotted to define the optimal processing conditions (Fig. 4). The heating rate

275 and peak temperature had a negative impact on the normalized oil absorption capacity.

276 The low heating temperature tended to lead to an increase of normalized oil absorption

277 capacity. The response surface revealed that maximum oil absorption capacity achieved

278 to $91.57(\mathrm{~g} / \mathrm{g})$ at peak temperature of $400{ }^{\circ} \mathrm{C}$ with heating rate of $0.20{ }^{\circ} \mathrm{C} / \mathrm{min}$. A possible

279 explanation of the phenomenon is that low pyrolysis temperature and low heating rate

280 could results to large sample volume. Volume of carbon aerogel processed under three

281 peak temperatures was compared and $400{ }^{\circ} \mathrm{C}$ heat-treated sample maintained larger

282 volume. Research on cellulose carbonization proved and claimed that dehydration is the

283 dominant reaction under low heating temperature [22]. The elimination of hydroxyl

284 groups induces double bonds, conjugated double bonds, consequently helps to maintain

285 the cellulose structure more stable and less accessible to thermal cleavage. Heating the

286 aerogel up to $400{ }^{\circ} \mathrm{C}$ only makes the sample experiencing the early stage of

287 carbonization, where thermal cleavage and scission are taken place. The volume of the

288 sample is fairly maintained at such low temperature. With the increasing of the heating

289 temperature, more well ordered stacking graphene sheets were formed through re-

290 polymerization with the releasing of gases and loose of non-carbon element, resulting to a

291 condensed and close packed aromatic structure, consequently the volume shrinkage [22]. 
292 Our previous research has demonstrated that macropores and the open pore structure

293 make the carbon aerogel to be efficient as oil absorbent [24]. Larger volume would

294 provide more open voids and drastically increase the oil absorption capacity.

295 The weight reduction of carbon aerogel affected by combination of peak temperature

296 and heating rate is plotted. Contour plot generated by the predictive model is shown in

297 Fig. 4(d). The interaction effect is obvious on the response. An increase of heating

298 temperature with heating rate up to the optimum point increased the weight reduction to

299 its maximum number, while further increase in heating temperature with heating rate

300 reversed the trend. In fact, the decrease of weight reduction on the contour plot is

301 achieved by decreasing in heating temperature below $700{ }^{\circ} \mathrm{C}$ or increasing in heating

302 temperature above $700{ }^{\circ} \mathrm{C}$, and increasing in heating rate above $6{ }^{\circ} \mathrm{C} / \mathrm{min}$ or decreasing in

303 heating rate below $6{ }^{\circ} \mathrm{C} / \mathrm{min}$. Again, the explanation for this is that the formed

304 intermediates oxidization components have the tendency to be taken away in the form of

$305 \mathrm{H}_{2} \mathrm{O}, \mathrm{CO}$, and $\mathrm{CO}_{2}$, when increasing the temperature to $700{ }^{\circ} \mathrm{C}$ or $1000{ }^{\circ} \mathrm{C}$. A lower

306 weight reduction is expected. The contour plot is used to find the feasible region for

307 optimized process. Each contour with number marked on stands for a particular height of

308 the corresponding response surface. It can be seen in Fig. 4 that at a low heating

309 temperature with heating rate less than $6{ }^{\circ} \mathrm{C} / \mathrm{min}$, decreasing heating rate reduced the

310 weight reduction of carbon aerogel. On the other hand, when heating rate was over $6{ }^{\circ} \mathrm{C}$

$311 / \mathrm{min}$, increasing heating rate reduced the weight reduction. A fast heating rate, for

312 example $10{ }^{\circ} \mathrm{C} / \mathrm{min}$, will cause "thermal inertia" effect, which results to less reaction

313 time to trigger decomposition. 
(a)

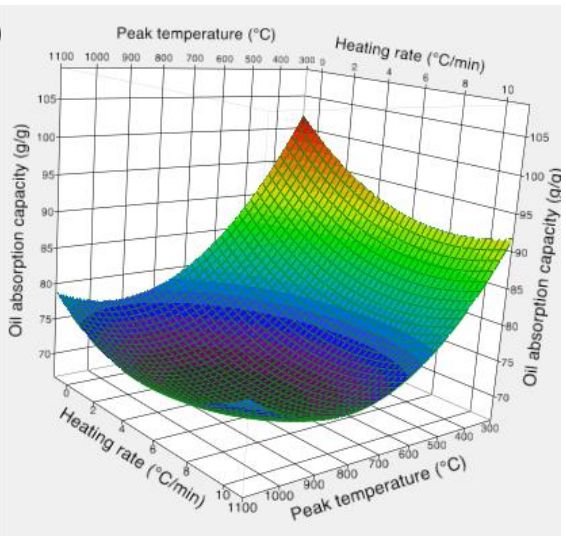

(c)

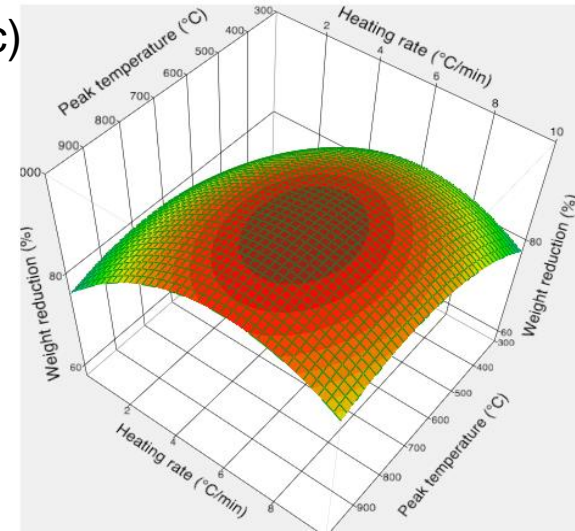

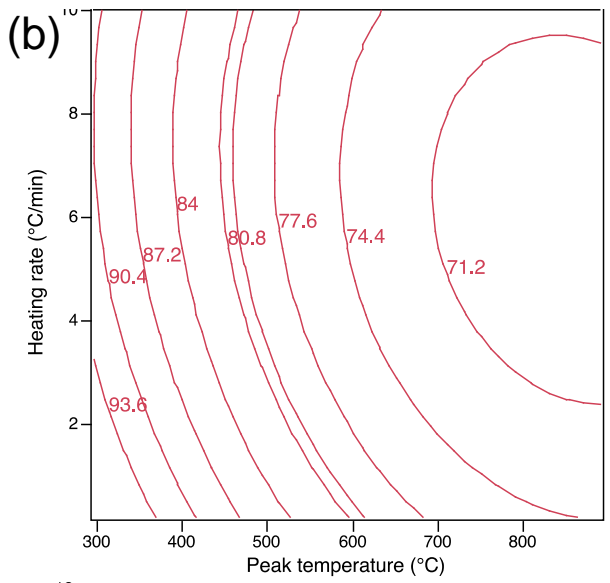

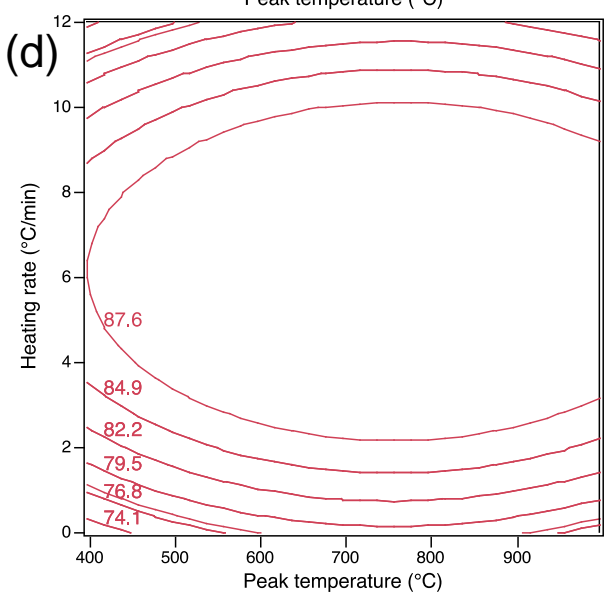

Fig. 4 (a) response surface plot and (b) contour profile representing the interaction between the variables affecting the normalized oil absorption capacity by oil density; (c) response surface plot and (d) contour profile representing the interaction between the variables affecting carbon yield after carbonization.

The optimization prediction plots shown in Fig. 5 (a) refers to prediction profile of optimum conditions for carbon aerogel. Graphic desirability traces for variable heat 323 temperature showed that decreasing heating temperature would achieve low weight

324 reduction and high oil absorption capacity. However, in order to achieve hydrophobic properties for the resulted product, heating temperature over $300{ }^{\circ} \mathrm{C}$ is necessary to 326 ensure thermal scission and removal of none carbon element in form of $\mathrm{H}_{2} \mathrm{O}, \mathrm{CO}_{2}$, and $327 \mathrm{CO}$. In addition, heating rate in the range of $6{ }^{\circ} \mathrm{C} / \mathrm{min}$ to $10^{\circ} \mathrm{C} / \mathrm{min}$ is more acceptable in 328 accordance with low energy input and high efficiency.

329 The overlaid contour plot is shown in Fig. 5 (b) with red contours revealing the 330 weight reduction and blue ones revealing oil absorption capacity. It is useful to visually 331 identify the feasible variables for multiple responses. Area highlighted by green dash 332 lines mapped out in overlaid contour plots instructs the operation levels for the feasible 
333 region for desired response in reality, in this case, a relatively high oil absorption capacity 334 and low weight reduction. In this particular case, area highlighted by green dash line is 335 more preferred and should be considered as a feasible operation region. As a result, one 336 of the optimum condition for making carbon aerogel is observed at peak temperature $=300$ $337{ }^{\circ} \mathrm{C}$ and heating rate $=8{ }^{\circ} \mathrm{C} / \mathrm{min}$, with an acceptable desirability value of 0.55 for all 338 responses.

(a)

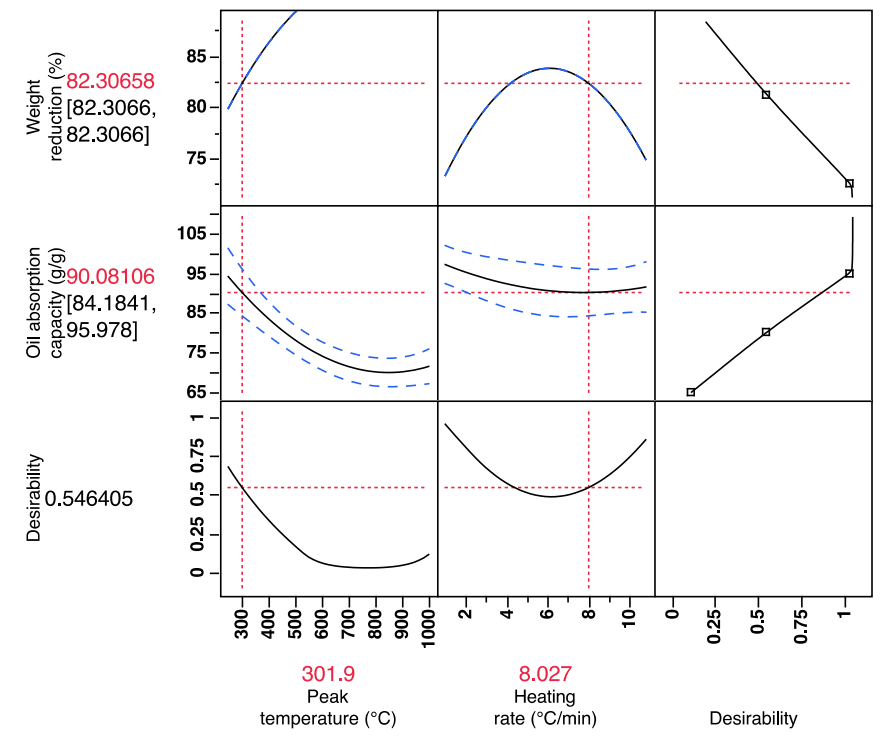

(b)

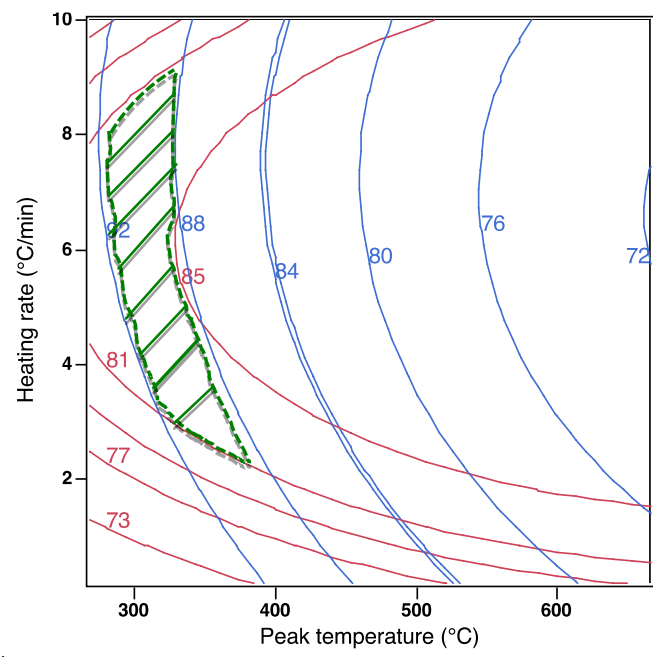

Fig. 5 (a) Optimization prediction plots and (b) overlaid contour plot for normalized oil absorption capacity $(\mathrm{g} / \mathrm{g})$ and weight reduction $(\%)$

Additional experiments runs were performed by randomly selecting combined operation parameters. NFC aerogel samples were carbonized under these selected conditions as summarized in Table 5. In this research, eight data points were collected for 
348 model validation, which accounts for $28 \%$ of the whole data set. Root mean square error 349 (RMSE) and coefficient of determination R-squared were used for assessing the fit of 350 regression model. The experimental and predicated response for normalized oil 351 absorption is plotted in Fig. 3 (c). The coefficient of determination R-squared $\left(\mathrm{R}^{2}\right)$ for 352 validation was calculated to be 0.58 , smaller than that calculated from training data $353\left(\mathrm{R}^{2}=0.88\right)$. The root mean square error value (RMSE) was 2.44 for validation data set, 354 very similar to the value for training data set (RMSE=2.90). These results indicate that 355 the constructed quadratic model is adequate for predicting the normalized oil absorption 356 capacity. On the other hand, from the plot of experimental and predicated response for 357 weight reduction in Fig. 3 (d), the R squared value was calculated to be 0.42 , smaller than 358 the value calculated from training data set $\left(\mathrm{R}^{2}=0.60\right)$. The root mean square error value 359 (RMSE) was 1.83 for validation data set, smaller than the value for training data set 360 (RMSE =4.38). Results also indicate that the constructed quadratic model has the ability 361 to predict the weight reduction. Model fitted for normalized oil absorption has a better 362 prediction than that for weight reduction.

Table 5. Comparison of model predicted and experimental values of normalized oil absorption and weight reduction (validation data set)

\begin{tabular}{|c|c|c|c|c|c|c|}
\hline \multirow[t]{2}{*}{$\begin{array}{l}\text { Run } \\
\text { order }\end{array}$} & \multirow{2}{*}{$\begin{array}{c}\text { Peak } \\
\text { temperature } \\
\left({ }^{\circ} \mathbf{C}\right)\end{array}$} & \multirow{2}{*}{$\begin{array}{c}\text { Heating } \\
\text { rate } \\
\left({ }^{\circ} \mathrm{C} / \mathrm{min}\right)\end{array}$} & \multicolumn{2}{|c|}{$\begin{array}{c}\text { Normalized oil absorption } \\
(\mathrm{g} / \mathrm{g})\end{array}$} & \multicolumn{2}{|c|}{$\begin{array}{l}\text { Normalized weight } \\
\text { reduction }(\%)\end{array}$} \\
\hline & & & Experimental & Predicted & Experimental & Predicted \\
\hline 1 & 350 & 6 & 75.42 & 86.83 & 81.53 & 85.95 \\
\hline 2 & 400 & 8 & 75.06 & 83.50 & 83.59 & 86.30 \\
\hline 3 & 400 & 8 & 74.43 & 83.50 & 81.62 & 86.30 \\
\hline 4 & 450 & 3 & 70.36 & 83.40 & 85.27 & 85.40 \\
\hline 5 & 450 & 3 & 68.57 & 83.40 & 80.97 & 85.40 \\
\hline 6 & 500 & 8 & 67.95 & 78.10 & 84.78 & 89.30 \\
\hline 7 & 500 & 6 & 67.26 & 78.20 & 84.68 & 90.70 \\
\hline 8 & 550 & 4 & 69.17 & 77.20 & 86.03 & 90.00 \\
\hline
\end{tabular}

370 To explain the discrepancy of oil absorption capacity and weight reduction from 371 carbon aerogel, carbonization process was further investigated by TGA analysis. Fig. 6

372 illustrates the relationship between temperature and weight/derivative weight percentage 373 of carbon aerogel. The curve shape is consistent with the TGA analysis performed on 
374 cellulose [26]. One should notice that a rapid weight loss step occurs in the range of 230 $375{ }^{\circ} \mathrm{C}$ to $320{ }^{\circ} \mathrm{C}$ for NFC aerogel. The extrapolated onset temperatures, denoted as the 376 temperature at which the weight loss begins, of carbon aerogel were estimated to be 259 $377{ }^{\circ} \mathrm{C}, 303{ }^{\circ} \mathrm{C}$ and $309{ }^{\circ} \mathrm{C}$ respectively corresponding to the heating rate of $0.20{ }^{\circ} \mathrm{C} / \mathrm{min}, 2$ $378{ }^{\circ} \mathrm{C} / \mathrm{min}$ and $10{ }^{\circ} \mathrm{C} / \mathrm{min}$. When performing carbonization on aerogel sample at low 379 temperature, such as below $400{ }^{\circ} \mathrm{C}$, carbon yield of CNF carbonized with low heating 380 rate is significantly increased compared to that of high heating rates. The effect of heating 381 rate during rapid mass loss $\left(230\right.$ to $\left.320^{\circ} \mathrm{C}\right)$ process on the char yield at $1000{ }^{\circ} \mathrm{C}$ was 382 compared. The trends highlighted in the insert of Fig. 6 (a) showed that heating rate had a 383 positive effect on the residual carbon yield. Char yield of carbonized aerogel exhibited 384 highest number of $12.60 \%$ with heating rate of $10{ }^{\circ} \mathrm{C} / \mathrm{min}$, while this number decreased 385 with the decrease of heating rate. The degradation temperatures of NFC aerogel were 386 calculated to appear at $302.30{ }^{\circ} \mathrm{C}$ when samples are heat-treated at low heating rate and 387 appeared at 351 to $354{ }^{\circ} \mathrm{C}$ when samples were heat-treated at high heating rate. 388 Apparently, for NFC sample with heating rate of $0.20^{\circ} \mathrm{C} / \mathrm{min}$, maxima in the rate of mass 389 change occurred at $302{ }^{\circ} \mathrm{C}$ and $360{ }^{\circ} \mathrm{C}$, however, their peak intensities were the lowest 390 among all other curves. Decomposition is triggered by temperature and started earlier 391 with low heating rate. Thermal cleavage and thermal scission mainly occur in the 392 temperature range of 240 to $400{ }^{\circ} \mathrm{C}$, whereby heating rate is various. Low heating rate 393 could provide sufficient reaction time to allow the heat dissipating into material, thus 394 leading to more loss of carbon atom in forms of $\mathrm{CO}$ and $\mathrm{CO}_{2}$. In the contrast, high heating 395 rate caused by temperature overshoot has a great potential to lead to "thermal inertia" 396 effect, consequently shift the onset and degradation temperatures to the right side. 
(a)

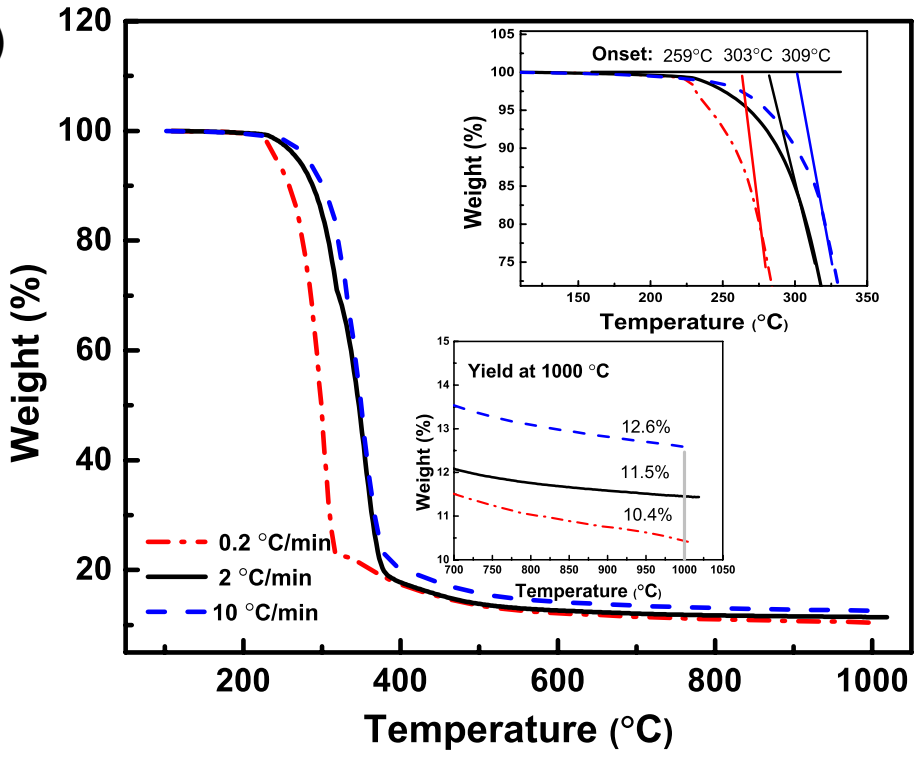

(b)

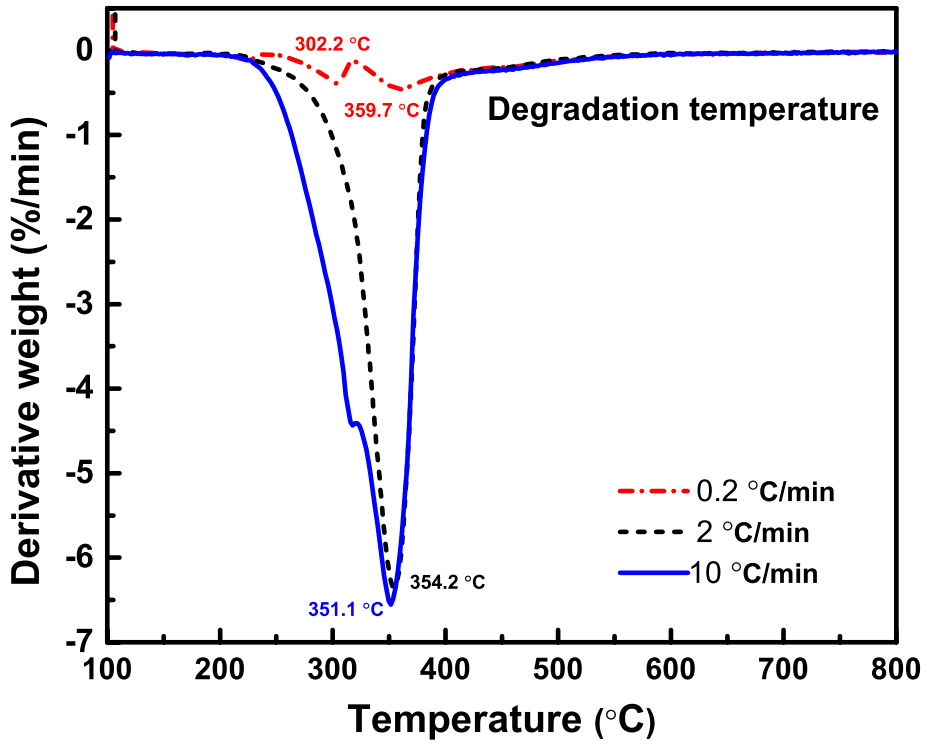

Temperature $\left({ }^{\circ} \mathrm{C}\right)$

Fig. 6 Thermogravimetric analysis (TGA) showing the effect of heating rate during temperature rising from 230 to $320{ }^{\circ} \mathrm{C}$ on carbon residual yield at $1000{ }^{\circ} \mathrm{C}$ (a) TGA curve and (b) DTG curve

\section{Conclusion}

406 from cellulose nanofibrils. We demonstrated that there exist the linkage between 407 carbonization operating process variables (peak temperature and heating temperature) 408 and the carbon aerogel performance (normalized oil absorption capacity, weight

409 reduction). The carbon aerogel making process has been successfully optimized by 410 adopting a statistical strategy of response surface methodology, in this case, faced 
411 centered central composite design (CCF). It was found that independent variables had

412 significant liner and quadratic effect on dependent variables. The optimum operating 413 conditions have been referred as peak temperature $=300{ }^{\circ} \mathrm{C}$ and heating rate $=8.00{ }^{\circ} \mathrm{C} / \mathrm{min}$

414 considering low energy input and high efficiency. The desirability for all responses reach

415 to 0.55 and it is acceptable. Compare to conventional single factor optimization methods,

416 which are time consuming and expensive with vague and misleading information, Design

417 of Experiment (DOE) method performed in this research and the resulted model provide

418 integrated and accurate results to systematically and effectively predict the response

419 through various independent variables.

420

421

422

423

424

425

426

427

428

429

430

431

432

433

434

435

436

437

438

439

440

441

442

443

444

445

446

447

448

449

\section{Acknowledgement}

The authors gratefully acknowledge the support of this research by USDA Special Wood Utilization Grants R11-0515-041 and R11-2219-510, the University of Tennessee, Department of Forestry, Wildlife and Fisheries, Center for Renewable Carbon, the financial support from the UTIA 2013 Innovation Grant and the Tennessee Experimental Station Project \#TEN00422 and the Agricultural Experiment Station McIntire-Stennis Grant TENOOMS-101.

\section{Reference}

[1] Nagel B, Pusz S, Trzebicka B. Review: tailoring the properties of macroporous carbon foams. J Mater Sci. 2014;49(1):1-17.

[2] Gui X, Li H, Wang K, Wei J, Jia Y, Li Z, et al. Recyclable carbon nanotube sponges for oil absorption. Acta Mater. 2011;59(12):4798-4804.

[3] Hu H, Zhao Z, Wan W, Gogotsi Y, Qiu J. Ultralight and highly compressible graphene aerogels. Adv Mater. 2013;25(15):2219-2223.

[4] Li H, Gui X, Zhang L, Wang S, Ji C, Wei J, et al. Carbon nanotube sponge filters for trapping nanoparticles and dye molecules from water. Chem Commun. 2010;46(42):7966-7968.

[5] Li Y, Samad YA, Polychronopoulou K, Alhassan SM, Liao K. Carbon aerogel from winter melon for highly efficient and recyclable oils and organic solvents absorption. Acs Sustian Chem Eng. 2014;2(6):1492-1497.

[6] Upadhyayula VKK, Deng S, Mitchell MC, Smith GB. Application of carbon nanotube technology for removal of contaminants in drinking water: A review. Sci Total Environ. 2009;408(1):1-13.

[7] Wu Z, Li C, Liang H, Chen J, Yu S. Ultralight, flexible, and fire-resistant carbon nanofiber aerogels from bacterial cellulose. Angew Chem Int Edit. 2013;52(10):29252929.

[8] Dong C, Zhang H, Pang Z, Liu Y, Zhang F. Sulfonated modification of cotton linter and its application as adsorbent for high-efficiency removal of lead(II) in effluent. Bioresource Technol. 2013;146(0):512-518. 
[9] Wu Q, Meng Y, Concha K, Wang S, Li Y, Ma L, et al. Influence of temperature and humidity on nano-mechanical properties of cellulose nanocrystal films made from

switchgrass and cotton. Ind Crop Prod. 2013;48(0):28-35.

[10] Wu Q, Meng Y, Wang S, Li Y, Fu S, Ma L, et al. Rheological behavior of cellulose nanocrystal suspension: Influence of concentration and aspect ratio. J Appl Polym Sci. 2014;131(15):40525-40533.

[11] Hubbe MA, Rojas OJ, Fingas M, Gupta BS. Cellulosic Substrates for Removal of Pollutants from Aqueous Systems: A Review. 3. Spilled Oil and Emulsified Organic Liquids2013.

[12] Moon R, Martini A, Nairn J, Simonsen J, Youngblood J. Cellulose nanomaterials review: structure, properties and nanocomposites. Chem Soc Rev. 2011;40(7):3941-3994. [13] Wang S, Cheng Q. A novel process to isolate fibrils from cellulose fibers by highintensity ultrasonication, part 1: process optimization. J Appl Polym Sci. 2009;113(2):1270-1275.

[14] Cheng Q, Wang S, Rials T, Lee S. Physical and mechanical properties of polyvinyl alcohol and polypropylene composite materials reinforced with fibril aggregates isolated from regenerated cellulose fibers. Cellulose. 2007;14(6):593-602.

[15] Ansell M. Wood: A 45th anniversary review of JMS papers. J Mater Sci. 2012;47(2):583-598.

[16] Ding J, Wang H, Li Z, Kohandehghan A, Cui K, Xu Z, et al. Carbon nanosheet frameworks derived from peat moss as high performance sodium ion battery anodes. ACS Nano. 2013;7(12):11004-11015.

[17] He L, Melnichenko Y, Gallego N, Contescu C, Guo J, Bahadur J. Investigation of morphology and hydrogen adsorption capacity of disordered carbons. Carbon. 2014;80:82-90.

[18] Wang H, Xu Z, Kohandehghan A, Li Z, Cui K, Tan X, et al. Interconnected Carbon Nanosheets Derived from Hemp for Ultrafast Supercapacitors with High Energy. ACS Nano. 2013;7(6):5131-5141.

[19] Tang M, Bacon R. Carbonization of cellulose fibers .1. low temperature pyrolysis. Carbon. 1964;1(3):390-390.

[20] Cagnon B, Py X, Guillot A, Stoeckli F, Chambat G. Contributions of hemicellulose, cellulose and lignin to the mass and the porous properties of chars and steam activated carbons from various lignocellulosic precursors. Bioresource Technol. 2009;100(1):292298.

[21] Li W, Yang K, Peng J, Zhang L, Guo S, Xia H. Effects of carbonization temperatures on characteristics of porosity in coconut shell chars and activated carbons derived from carbonized coconut shell chars. Ind Crop Prod. 2008;28(2):190-198. [22] Dumanli AG, Windle AH. Carbon fibres from cellulosic precursors: a review. J Mater Sci. 2012;47(10):4236-4250.

[23] Huang X. Fabrication and properties of carbon fibers. Materials. 2009;2(4):23692403.

[24] Meng Y, Young T, Liu P, Contescu C, Huang B, Wang S. Ultralight carbon aerogel from nanocellulose as a highly selective oil absorption material. Cellulose. 2014:1-13. [25] Montgomery DC. Design and Analysis of Experiments, 8th Edition: John Wiley \& Sons, Incorporated; 2012. 
495 [26] Milosavljevic I, Suuberg EM. Cellulose thermal decomposition kinetics: global mass 496 loss kinetics. Ind Eng Chem Res. 1995;34(4):1081-1091.

497 [27] Silva F, Rodrigues M, Maugeri F. Dynamic modelling, simulation and optimization 498 of an extractive continuous alcoholic fermentation process. J Chem Technol Biotechnol 499 1999;74(2):176-182.

500 [28] Brunner P, Roberts P. The significance of heating rate on char yield and char 501 properties in the pyrolysis of cellulose. Carbon. 1980;18(3):217-224.

502 
Graphical Abstract

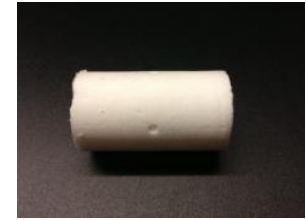

NFC aerogel
Carbonization

Peak temperature Heating rate
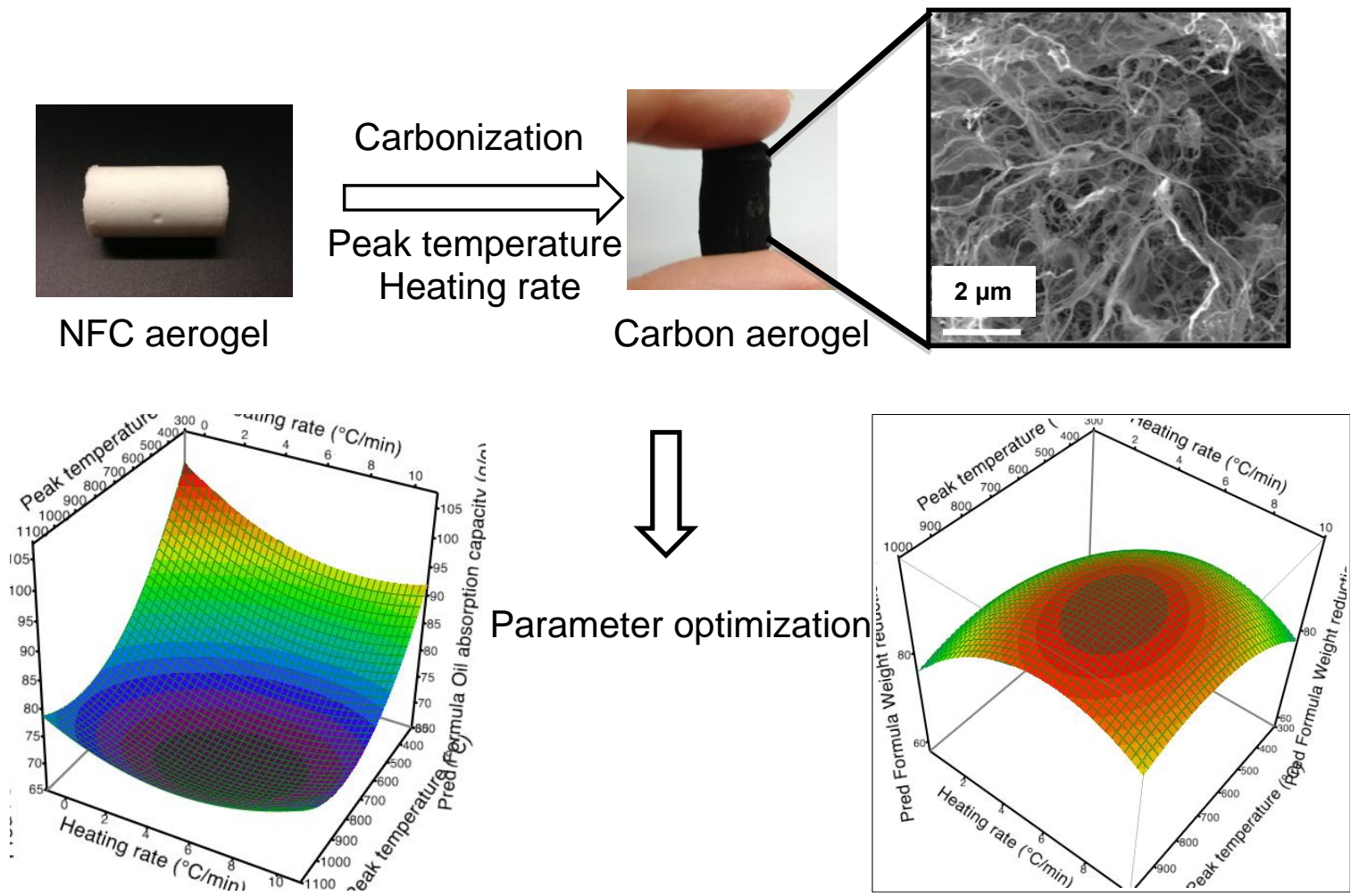